\title{
Investigation of anemia risk factors and its related outcomes in patients with ST-elevation myocardial infarction
}

\author{
Alireza Rai ${ }^{1}$, Mehran Babanejad ${ }^{2}$, Samira Sanadgol ${ }^{1}$, Hosein Karim*3 (D) ${ }^{\text {Parisa Janjani }}{ }^{1}$, Amir Reza Rai $^{4}$, \\ Afshar Shahmohammadi ${ }^{5}$
}

Received: 8 Dec 2016

Published: 3 Sep 2020

\section{Abstract}

Background: Anemia is one of the symptoms of hospital patients suffering from ST-elevation myocardial infarction (STEMI), which may have a predictive role in short- or long-term complications. This study aimed to identify anemia risk factors and related short- or long-term outcomes in STEMI patients.

Methods: This was a prospective study of patients older than 18 years diagnosed with STEMI who admitted to Imam Ali hospital from 2014 to 2015 . To collect demographic and clinical information related to anemia, a questionnaire compiled by researchers was administered. The collected data were analyzed by SPSS (version 20); also, independent $t$ test and multiple logistic regression analyses were applied to find related risk factors of anemia in STEMI patients. Significance level was set at $\mathrm{p}<0.05$ for all statistical tests.

Results: In total, $49(11.7 \%)$ out of 423 patients suffered from anemia. STEMI patients with anemia were more likely to be female $(\mathrm{OR}=2.92 ; \mathrm{CI} 95 \%=1.58-5.38)$, diabetic $(\mathrm{OR}=2.5 ; \mathrm{CI} 95 \%=1.32-4.74), \geq 60$ years old $(\mathrm{OR}=2.42 ; \mathrm{CI} 95 \%=1.24-4.73)$ nonsmokers $(\mathrm{OR}=2.18$; $\mathrm{CI} 95 \%=1.07-4.4)$, and susceptible to require in-hospital cardiopulmonary resuscitation $(\mathrm{CPR}),(\mathrm{OR}=3.12$; CI $95 \%=1.35-7.1)$. In the final analysis, using the Forward Wald model in logistic regression, anemia remained significantly related to female gender $(\mathrm{OR}=2.76$; CI 95\% $=1.42-5.36)$, diabetes mellitus $(\mathrm{OR}=2.38$; $\mathrm{CI} 95 \%=1.2-4.74)$, and a history of $\mathrm{MI}(\mathrm{OR}=2.5$; CI $95 \%=1.04-6.11)$.

Conclusion: STEMI patients with anemia are more susceptible to have in-hospital outcomes. Furthermore, female gender, hyperglycemia, and history of MI were factors related to anemia that might have major role in the complications of STEMI.

Keywords: ST-elevation myocardial infarction, Anemia, Risk factors, Mortality

Conflicts of Interest: None declared

Funding: Kermanshah University of Medical Sciences (number: 93171)

\section{*This work has been published under CC BY-NC-SA 1.0 license.}

Copyright $\odot$ Iran University of Medical Sciences

Cite this article as: Rai A, Babanejad M, Sanadgol S, Karim H, Janjani P, Rai AR, Shahmohammadi A. Investigation of anemia risk factors and its related outcomes in patients with ST-elevation myocardial infarction. Med J Islam Repub Iran. 2020 (3 Sep);34:113. https://doi.org/10.47176/mjiri.34.113

\section{Introduction}

Acute coronary syndrome (ACS) covers a wide range of diseases from unstable angina to myocardial infarction (MI). MI is diagnosed through clinical findings such as

Corresponding author: Dr Hosein Karim, h.karim@abzums.ac.ir

1. Cardiovascular Research Center, Health Institute, Kermanshah University of Medical Sciences, Kermanshah, Iran

2. Social Determinants of Health Research Center, Saveh University of Medical Sciences, Saveh, Iran

3. Department of Cardiology, School of Medicine, Alborz University of Medical Sciences, Karaj, Iran

4. Faculty of Medicine, Azad University of Medical Sciences, Unit of Tehran, Tehran, Iran

5. Unit of Development and Research of Taleghani and Imam Ali Hospitals, Kermanshah University of Medical Sciences, Kermanshah, Iran electrocardiography (ECG), increased level of blood biomarkers, and imaging. MI confirmed by ECG patterns is displayed as ST-segment elevation MI (STEMI) or non-

\section{$\uparrow$ What is "already known" in this topic:}

Anemia, as one of the complications associated with acute coronary syndrome, including myocardial infarction, can have a predictive role in the incidence of in-hospital or long-term outcomes. Although anemia may be related to several factors in STEMI patients, the pattern of these association is not specified in our society.

\section{$\rightarrow$ What this article adds:}

Anemia may increase the complications of STEMI patients, especially in hospital outcomes, when they are admitted to the hospital. In addition, female gender, hyperglycemia, and history of MI are most important factors related to anemia that may have a major role in the complications of STEMI. 
ST-segment elevation MI (1). Despite the reduced incidence of STEMI in the last decade, it accounts for $25 \%$ to $40 \%$ of MI cases (2-4).

Anemia, as one of the complications associated with ACS patients, can have a predictive role in the incidence of in-hospital or long-term outcomes (5-7). Different studies have revealed an association between the level of hemoglobin and in-hospital complications among STEMI patients $(8,9)$. Iron deficiency is one of the most common causes of anemia among adults in the Middle East and North Africa. It has also been proved that STEMI patients' epidemiological examination in terms of risk factors and used strategies is significantly different from that employed in developed countries. For instance, primary percutaneous coronary intervention (P.PCI) has not yet been considered as the main strategy in the treatment of STEMI patients. Therefore, evaluating the relationship of anemia with outcomes and risk factors of MI seems to be essential in developing countries. In the literature review, there was no comprehensive study in Iran, especially in Kermanshah, to evaluate the relationship between in-hospital risk factors (eg, low ejection fraction, streptokinase uptake) and in-hospital outcomes (eg, cardiopulmonary resuscitation (CPR), mortality from anemia), except for a limited study aimed at examining the relationship between both serum ferritin and iron with the presence of diabetes in STEMI patients (10). Accordingly, this study was conducted to determine the risk factors and in-hospital clinical outcomes related to anemia among STEMI patients in Imam Ali hospital, Kermanshah.

\section{Methods}

This prospective study examined a sample of STEMI patients over 18 years who were admitted to Imam Ali hospital, Kermanshah, using convenient sampling. At first, the demographic and clinical information and inhospital complications of all patients admitted to the hospital from March 22, 2014 to September 22, 2015 were recorded. Then, all patients were followed up 1 year later only in terms of mortality rate, but the interval times such as monthly mortality were not recorded during the year. In-hospital patients were defined as patients whose complications occurred between hospital arrival and hospital discharge. After the MI event was diagnosed and confirmed by the cardiologist, all information about the diagnosed condition and demographic and clinical information was collected via a research-made questionnaire. The validity of the questions was approved by 5 cardiologists who analyzed the content.

The questionnaire consisted of 2 sections. The first section collected background and demographic information about the patients' age and gender, history of hypertension or taking blood pressure medication, diabetes, or taking hypoglycemic drugs, hyperlipidemia, MI, cerebrovascular attack (CVA), and current smoking. The history of patients and their cardiovascular risk factors was collected on admission or during the first 24 hours. The second section of the questionnaire covered the in-hospital and clinical features and 1-year mortality and included the following variables: cardiogenic shock, CPR, ejection fraction
(EF) $(40 \leq$ and less), streptokinase administration, P-PCI, and the patients' in-hospital and 1-year mortality. Cardiogenic shock was characterized by a persistent drop in systolic blood pressure (less than $90 \mathrm{mmHg}$ for $>30$ minutes) and reduced cardiac index $(<2.2 \mathrm{~L} /$ minute $/ \mathrm{m} 2)$ and pulmonary capillary wedge pressure $(>18 \mathrm{~mm} \mathrm{Hg})(11)$. In addition, the scale score reliability of Cronbach alpha was estimated at 0.74 in this study, which was acceptable (12). Those patients who underwent CPR on arrival and needed it during their hospitalization were excluded from the study due to their different health conditions. 1-year mortality was recorded by the cardiologist by calling the number recorded on the related form. Those who were not available, were called again after 1 or 2 weeks to check their survival status, and if they were not available, the hospital's Health Information System was used to examine their mortality. Finally, if their survival status remained unknown, they were considered as censored data.

To perform the necessary tests for MI patients, a blood sample was taken on admission. In the present study, anemia was defined according to WHO standards in which anemic condition is defined as a hemoglobin level lower than $13 \mathrm{~g} / \mathrm{dL}$ and $12 \mathrm{~g} / \mathrm{dL}$ for men and women, respectively (13), and the relationship between the above mentioned demographic and clinical variables in anemic and nonanemic patients was compared.

This study has taken the necessary ethical steps when investigating and collecting information. To obtain consent, the researcher talked to patients face to face and explained the aim of the study and reassured them that the information would remain confidential. When some STEMI patients were not able to provide the demographic information, their first-degree family answered the questions. The study project number and ethical approval code of the study were 93171 and KUMS.ARBC.1395.819, respectively.

\section{Statistical analysis}

Finally, the collected data were analyzed by SPSS (version 20). An independent $t$ test was used to show the differences between age and anemia. To estimate the odds ratio $(\mathrm{OR})$ of the desired variables, a multiple logistic regression analysis was used and the variables of age group, gender, history of diabetes, smoking, history of MI, inhospital CPR, EF, and streptokinase, with p-value $<0.2$ in univariate analysis, were entered into the multiple logistic regression analysis using the enter method. After the multiple analyses, the Forward Wald method was used to find the variables that had a stronger relationship with anemia independently. Since the data included only 1-year mortality, and monthly mortality was not recorded, the Cox regression analysis was not applied. Significance level for multiple analyses was set at $\mathrm{p}<0.05$ for all statistical tests.

\section{Results}

The present study examined 480 hospitalized STEMI patients. Of the patients, 57 were excluded from the study because they did not give their consent. Ultimately, 423 patients were investigated and all were followed up 1 year 
later in terms of mortality. Also, 36 patients were censored after the 1-year follow-up. Moreover, 314 (74.2\%) patients were male and the rest were female.

In general, 49 out of 423 STEMI patients (11.7\%) suffered from anemia. The mean and standard deviation of the patients' age was $66.17 \pm 13.25$ among anemic patients and $60.97 \pm 12.57$ among nonanemic patients, which indicated a significant difference $(p=0.008)$. Patients with anemia were more likely to be $\geq 60$ years old $(\mathrm{OR}=2.42$; CI $95 \%=1.24-4.73)$, female $(\mathrm{OR}=2.92$; CI $95 \%=1.58$ 5. 38), diabetic $(\mathrm{OR}=2.5$; CI $95 \%=1.32-4.74)$, and nonsmokers $(\mathrm{OR}=2.18 ; \mathrm{CI} 95 \%=1.07-4.4)$. However, there was no relationship between anemia and hypertension, dyslipidemia, MI, and CVA (Table 1).
Patients with anemia were more likely to require CPR during their hospitalization $(\mathrm{OR}=3.12$; CI 95\% $=1.35$ 7.1), while this relationship was not seen between anemia and cardiogenic shock, EF, streptokinase administration, primary PCI, in-hospital, and 1-year mortality (Table 2).

After performing a multiple analysis, having anemia had a significant association with history of diabetes mellitus, while this relationship did not remain for age group, gender, smoking, history of MI, in-hospital CPR, EF, and streptokinase. In the enter method, considering those variables which were eligible in the univariate model, anemic patients were more likely to be diabetic $(\mathrm{OR}=2.43$; $\mathrm{CI}$ $95 \%=1.2-4.92)($ Table 3$)$.

In the multiple analysis, the use of the Forward Wald

Table 1. Demographic characteristics of ST-elevation myocardial infarction patients according to the presence of anemia

\begin{tabular}{|c|c|c|c|c|}
\hline Variables & $\begin{array}{l}\text { Nonanemic } \\
\text { No. }(\%)\end{array}$ & $\begin{array}{l}\text { Anemic } \\
\text { No. (\%) }\end{array}$ & $P$ value & $\begin{array}{c}\text { Crude } \\
\text { OR }(95 \% \mathrm{CI})\end{array}$ \\
\hline Mean age $( \pm \mathrm{SD})$ & $60.97( \pm 12.57)$ & $66.17( \pm 13.25)$ & 0.008 & $1.03(1.00-1.06)$ \\
\hline \multicolumn{5}{|l|}{ Age group(year) } \\
\hline$<60$ & $175(47.4)$ & $13(27.1)$ & & 1 \\
\hline$\geq 60$ & $194(52.6)$ & 35 (72.9) & 0.009 & $2.42(1.24-4.73)$ \\
\hline \multicolumn{5}{|l|}{ Gender } \\
\hline Female & $86(23.2)$ & $23(46.9)$ & 0.001 & $2.92(1.58-5.38)$ \\
\hline Male & $284(76.8)$ & $26(53.1)$ & & 1 \\
\hline \multicolumn{5}{|l|}{ History of HTN } \\
\hline No & $216(58.5)$ & $24(49.0)$ & & 1 \\
\hline Yes & $153(41.5)$ & $25(51.0)$ & 0.201 & $1.47(0.8-2.67)$ \\
\hline \multicolumn{5}{|c|}{ History of Diabetes } \\
\hline No & $296(80.7)$ & $30(62.5)$ & & 1 \\
\hline Yes & $71(19.3)$ & $18(37.5)$ & 0.005 & $2.5(1.32-4.74)$ \\
\hline \multicolumn{5}{|l|}{ Hyperlipidemia } \\
\hline No & $293(85.7)$ & $37(78.7)$ & & 1 \\
\hline Yes & $49(14.3)$ & $10(21.3)$ & 0.212 & $1.61(0.75-3.46)$ \\
\hline \multicolumn{5}{|l|}{ Current Smoker } \\
\hline No & $213(59.3)$ & $35(76.1)$ & & $2.18(1.07-4.43)$ \\
\hline Yes & $146(40.7)$ & $11(23.9)$ & 0.030 & 1 \\
\hline \multicolumn{5}{|l|}{ History of MI } \\
\hline No & $334(90.5)$ & $40(81.6)$ & 0.060 & 1 \\
\hline Yes & $35(9.5)$ & $9(18.4)$ & & $2.14(0.96-4.79)$ \\
\hline \multicolumn{5}{|l|}{ History of CVA } \\
\hline No & 347 (94.8) & $47(95.9)$ & 0.701 & $1.28(0.3-5.7)$ \\
\hline Yes & $19(5.2)$ & $2(4.1)$ & & 1 \\
\hline
\end{tabular}

Table 2 .The in-hospital outcomes and 1-year mortality in patients presenting for ST-elevation myocardial infarction according to the presence of anemia

\begin{tabular}{|c|c|c|c|c|}
\hline Variables & $\begin{array}{c}\text { Nonanemic } \\
\text { No. }(\%)\end{array}$ & $\begin{array}{l}\text { Anemic } \\
\text { No. }(\%) \\
\end{array}$ & $P$ value & $\begin{array}{c}\text { Crude } \\
\text { OR }(95 \% \mathrm{CI})\end{array}$ \\
\hline \multicolumn{5}{|c|}{ Cardiogenic shock } \\
\hline No & $354(95.7)$ & $45(91.8)$ & & 1 \\
\hline Yes & $16(4.3)$ & $4(8.2)$ & 0.240 & $1.96(0.63-6.14)$ \\
\hline \multicolumn{5}{|c|}{ In hospital CPR } \\
\hline No & $338(93.1)$ & $39(81.3)$ & & 1 \\
\hline Yes & $25(6.9)$ & $9(18.7)$ & 0.007 & $3.12(1.35-7.16)$ \\
\hline \multicolumn{5}{|c|}{ Ejection fraction } \\
\hline$\leq 40$ & $210(58.2)$ & $32(68.1)$ & & $1.53(0.8-2.93)$ \\
\hline$>40$ & $151(41.8)$ & 15 (31.9) & 0.110 & 1 \\
\hline \multicolumn{5}{|c|}{ Streptokinase } \\
\hline No & $89(24.3)$ & 17 (34.7) & & $1.65(0.88-3.13)$ \\
\hline Yes & $278(75.7)$ & $32(65.3)$ & 0.129 & 1 \\
\hline \multicolumn{5}{|l|}{ P.PCI } \\
\hline No & $324(91.8)$ & $43(91.5)$ & & 1 \\
\hline Yes & $29(8.2)$ & $4(8.5)$ & 0.904 & $1.03(0.34-3.1)$ \\
\hline \multicolumn{5}{|c|}{ In-hospital mortality } \\
\hline No & $344(93.0)$ & $43(87.8)$ & & 1 \\
\hline Yes & $26(7.0)$ & $6(12.2)$ & 0.207 & $1.85(0.7-4.73)$ \\
\hline \multicolumn{5}{|c|}{ One-year mortality } \\
\hline No & $314(91.5)$ & $37(86.0)$ & 0.202 & 1 \\
\hline Yes & $29(8.5)$ & $6(14.0)$ & & $1.75(0.68-4.5)$ \\
\hline
\end{tabular}






model ultimately resulted in a final OR for the relationship between anemia and female patients $(\mathrm{OR}=2.76$; CI $95 \%$ $=1.42-5.36)$, diabetes mellitus $(\mathrm{OR}=2.38$; CI 95\% $=1.2$ 4.74), and MI history (OR $=2.5$; CI 95\% = 1.04-6.11). Also, pseudo R square for these 3 ORs was 0.1 . In other words, these 3 variables had the highest association with anemia among STEMI patients.

\section{Discussion}

This study aimed to determine anemia risk factors and related short- or long-term outcomes in STEMI patients. This study showed that anemia was significantly more in females and diabetic patients. STEMI patients with anemia had a higher in-hospital mortality but it was not significant. Eventually, in-hospital CPR was higher in anemic patients.

Anemia, which is due to iron deficiency, is the most important micronutrient deficiency worldwide. The condition is common in both developing and developed countries, but is more prevalent among women. Anemia may lead to several chronic complications if it remains untreated (14). This study demonstrated that the chance of anemia was higher among women than among men. Several studies have proven the high prevalence of anemia among female patients suffering a heart attack $(5,7,15,16)$. Some studies on MI patients demonstrated that the hemoglobin level in women was significantly lower than that in men $(17,18)$, which is an indicator of female susceptibility to this complication. However, some studies suggest that the frequency of anemia was similar among male and female with STEMI (15).

This study revealed that anemia is twice more common in diabetic patients than in the nondiabetic. Generally, the rate of anemia in diabetic patients, regardless of MI, was 2 to 3 times more compared to nondiabetic patients (19); this can account for MI patients as well. In the study conducted by Jomaa et al (2016), 1498 STEMI patients were examined, and the findings revealed that the incidence of diabetes in anemic patients was significantly more than nondiabetic patients (17). Sulaiman et al (2012) also supported the prevalence of anemia in half of the patients with acute coronary syndrome (20). In fact, it can be argued that diabetes can not only independently result in mortality, but can also increase the chance of MI and mortality if it is complicated by anemia; therefore, the importance of its prognosis should not be ignored (21).

Based on the findings, there was no significant association between anemia and in-hospital and 1-year mortality. However, anemia was more prevalent among patients who died. Most previous studies have confirmed the association between anemia and in-hospital and 1-year mortality, especially among STEMI patients; as an independent variable, anemia increases the cardiovascular mortality rate (20-22). Nevertheless, another study on MI patients was in line with the findings of this study. Mortality rate was not significant in patients who were diagnosed with anemia, according to the ninth edition of coding the International Classification of Diseases (5). The hemoglobin level in the primary assessment of STEMI patients can strongly and independently predict these patients' cardiovascular outcomes such as mortality. There is a J-shape relationship between the hemoglobin level on admission and clinical outcomes, so the mortality rate increases due to cardiovascular disorders among the patients with a hemoglobin level lower than $14 \mathrm{~g} / \mathrm{dL}$. Likewise, mortality rate increases when the hemoglobin level is more than $17 \mathrm{~g} / \mathrm{dL}$ (11). Consequently, both ranges in STEMI patients should be taken into account as a risk factor leading to mortality.

Anemia increased the odds of in-hospital PCR at univariate level by 3 times; however, the impact of this amount of OR and its level of significance were eliminated after reducing and balancing the intervening variables. The frequency of cardiogenic shock, which mainly leads to $\mathrm{CPR}$, was higher in anemic patients. Considering the 
close relationship between the occurrence of in-hospital outcomes such as cardiogenic shock and the amount of inhospital CPR and also considering that some studies supported the relationship between cardiogenic shock and anemia $(17,20)$, it can be maintained that the need for inhospital CPR is influenced by the level of anemia in the sample of the study. On the other hand, according to above-mentioned studies, anemic patients have a higher mortality rate. Since in-hospital mortality occurs after the administration of CPR, patients who undergo CPR can be classified as a group whose level of anemia is higher than those who do not receive CPR. However, more studies with large sample sizes can lead to a more generalizable relationship.

\section{Limitation}

As a limitation, self-reporting method was used to document other health issues in the elderly, making it susceptible to social desirability bias. Thus, if possible, this should be minimized in future studies (23).

\section{Advantages}

The results of this study on STEMI patients with anemia can be useful to prevent severe in-hospital outcomes. In addition, obtained information on clinical history and demographic characteristics of STEMI patients with anemia can avoid unwanted complications.

\section{Conclusion}

It seems that there are several related factors for anemia in STEMI patients that may increase the complications of the disease. In addition, STEMI patients with anemia can be considered as a high-risk group of in-hospital outcomes when they are admitted to the hospital. Future studies should be conducted to examine the relationship between anemia and CPR in STEMI patients with larger sample sizes. In addition, the frequency of mortality in the anemic patients was higher. However, there was no significant association between anemia with in-hospital and 1-year mortality in STEMI patients. Furthermore, female gender, hyperglycemia, and history of MI are most important factors related to anemia that may have a major role in the complications of STEMI.

\section{Acknowledgements}

We would like to thank all those who cooperated in this study, especially the personnel and participants who were truly cooperative in all stages of this project. This study, numbered 93171, was a part of a PhD thesis on cardiovascular disease at Kermanshah University of Medical Sciences.

\section{Conflict of Interests}

The authors declare that they have no competing interests.

\section{References}

1. Thygesen K, Alpert JS, Jaffe AS, Simoons ML, Chaitman BR, White HD, et al. Third universal definition of myocardial infarction. J Am Coll Cardiol. 2012;60(16):1581-98.

2. Mehta RH, Parsons L, Rao SV, Peterson ED. Association of
Bleeding and In-Hospital Mortality in Black and White Patients With ST-Segment-Elevation Myocardial Infarction Receiving Reperfusion. Circulation. 2012;125(14):1727-34.

3. Fox KA, Steg PG, Eagle KA, Goodman SG, Anderson FA, Granger $\mathrm{CB}$, et al. Decline in rates of death and heart failure in acute coronary syndromes, 1999-2006. JAMA. 2007;297(17):1892-900.

4. Yeh RW, Sidney S, Chandra M, Sorel M, Selby JV, Go AS. Population trends in the incidence and outcomes of acute myocardial infarction. N Engl J Med. 2010;362(23):2155-65.

5. Al Falluji N, Lawrence-Nelson J, Kostis JB, Lacy CR, Ranjan R, Wilson AC. Effect of anemia on 1-year mortality in patients with acute myocardial infarction. Am Heart J. 2002;144(4):636-41.

6. Sabatine MS, Morrow DA, Giugliano RP, Burton PB, Murphy SA, McCabe $\mathrm{CH}$, et al. Association of hemoglobin levels with clinical outcomes in acute coronary syndromes. Circulation. 2005;111(16):2042-9.

7. Tsujita K, Nikolsky E, Lansky AJ, Dangas G, Fahy M, Brodie BR, et al. Impact of anemia on clinical outcomes of patients with STsegment elevation myocardial infarction in relation to gender and adjunctive antithrombotic therapy (from the HORIZONS-AMI trial). Am J Cardiol. 2010;105(10):1385-94.

8. Lipšic E, van der Horst IC, Voors AA, van der Meer P, Nijsten MW, van Gilst WH, et al. Hemoglobin levels and 30-day mortality in patients after myocardial infarction. Int J Cardiol. 2005;100(2):28992.

9. Aronson D, Suleiman M, Agmon Y, Suleiman A, Blich M, Kapeliovich M, et al. Changes in haemoglobin levels during hospital course and long-term outcome after acute myocardial infarction. Eur Heart J. 2007;28(11):1289-96.

10. Nia HS, Haghdoost AA, Chan YH, Tabari F, Hashemi A, Alaei B, et al. Serum ferritin and iron in diabetic and non-diabetic with acute myocardial infarction. Life Sci. 2012;9(4):2740-5.

11. Mann DL, Zipes DP, Libby P, Bonow RO, Braunwald E. Braunwald's heart disease: a textbook of cardiovascular medicine. Elsevier/Saunders; 2015.

12. Nunnally JC. Assessment of Reliability. In: Psychometric Theory (2nd ed.). New York: McGraw-Hill.1978.

13. World Health Organization. Iron deficiency anaemia: assessment, prevention and control: a guide for programme managers. 2001.

14. Armstrong GR, Summerlee AJ. The Etiology, Treatment and Effective Prevention of Iron Deficiency and Iron Deficiency Anemia in Women and Young Children Worldwide: A Review. J Womens Health Care. 2014;2015.

15. Nikolsky E, Aymong ED, Halkin A, Grines CL, Cox DA, Garcia $\mathrm{E}$, et al. Impact of anemia in patients with acute myocardial infarction undergoing primary percutaneous coronary intervention: analysis from the Controlled Abciximab and Device Investigation to Lower Late Angioplasty Complications (CADILLAC) Trial. J Am Coll Cardiol. 2004;44(3):547-53.

16. Lincoff AM, Bittl JA, Harrington RA, Feit F, Kleiman NS, Jackman JD, et al. Bivalirudin and provisional glycoprotein IIb/IIIa blockade compared with heparin and planned glycoprotein IIb/IIIa blockade during percutaneous coronary intervention: REPLACE-2 randomized trial. JAMA. 2003;289(7):853-63.

17. Jomaa W, Ali IB, Hamdi S, Azaiez MA, El Hraïech A, Hamda KB, et al. Prevalence and prognostic significance of anemia in patients presenting for ST-elevation myocardial infarction in a Tunisian center. J Saudi Heart Assoc. 2016.

18. Anker SD, Voors A, Okonko D, Clark AL, James MK, von Haehling S, et al. Prevalence, incidence, and prognostic value of anaemia in patients after an acute myocardial infarction: data from the OPTIMAAL trial. Eur Heart J. 2009;30(11):1331-9.

19. Thomas MC, MacIsaac RJ, Tsalamandris C, Power D, Jerums G. Unrecognized Anemia in Patients With Diabetes A cross-sectional survey. Diabetes care. 2003;26(4):1164-9.

20. Sulaiman K, Prashanth P, Al-Zakwani I, Al-Mahmeed W, AlMotarreb A, Al Suwaidi J, et al. Impact of anemia on in-hospital, one-month and one-year mortality in patients with acute coronary syndrome from the Middle East. Clin Med Res. 2012;10(2):65-71.

21. Shu DH, Ransom TP, O'Connell CM, Cox JL, Kaiser SM, Gee SA, et al. Anemia is an independent risk for mortality after acute myocardial infarction in patients with and without diabetes. Cardiovasc Diabetol. 2006;5(1):1.

22. Kruk M, Przyłuski J, Kalińczuk Ł, Pręgowski J, Kaczmarska E, Petryka J, et al. Clustering of admission hyperglycemia, impaired 
Anemia in ST-elevation myocardial infarction patients

renal function and anemia and its impact on in-hospital outcomes in patients with ST-elevation myocardial infarction. Atherosclerosis. 2010;209(2):558-64.

23. Grimm P. Social desirability bias. Wiley International Encyclopedia of Marketing. 2010. 